\title{
Effect of sampling location, release technique and time after activation on the movement characteristics of scallop (Pecten maximus) sperm
}

\author{
Marc SuQueT $^{1, a}$, Claudie QuÉRÉ ${ }^{2}$, Christian Mingant ${ }^{1}$, Luc Lebrun ${ }^{1}$, Dominique RATISKOL ${ }^{1}$, \\ Philippe MINER $^{2}$ and Jacky COSSON ${ }^{3}$ \\ 1 Ifremer, UMR 6539, Physiologie fonctionnelle des organismes marins, Station expérimentale d'Argenton, Argenton, France \\ 2 Ifremer, UMR 6539, Physiologie fonctionnelle des organismes marins, Plouzané, France \\ 3 University of South Bohemia in Ceske Budejovice, Faculty of Fisheries and Protection of Waters, South Bohemian Research Center \\ of Aquaculture and Biodiversity of Hydrocenoses, 38925 Vodnany, Czech Republic
}

Received 26 October 2012; Accepted 15 March 2013

\begin{abstract}
Sperm characteristics of scallops have not been well described in the scientific literature. The effects of sperm release technique (thermal shock versus serotonin injection), of sperm collection technique (testis sampling versus serotonin injection), of sperm sampling location along the genital tract, of in vitro sperm maturation, and of time post activation on scallop sperm characteristics were assessed in the present work. Whatever sperm release technique used, no significant differences were observed regarding the percentage of motile spermatozoa and the velocity of the average path (VAP). Compared to testicular sperm, a higher percentage of motile spermatozoa, VAP and intracellular adenosine triphosphate (ATP) content were observed for sperm shed after serotonin injection. From the distal part of testes up to the gonopore, an increase of the percentage of motile spermatozoa and VAP was assessed, suggesting a sperm 'maturation process' along the genital ducts. A higher increase in the percentage of motile sperm was recorded during a 5 min incubation of testicular sperm in seawater containing $2 \mathrm{mM}$ serotonin and seawater containing $10 \mathrm{mM}$ caffein compared to seawater (control). In addition, a higher VAP was assessed, incubating testicular sperm in caffein, compared to control or serotonin. Then, the percentage of motile spermatozoa, VAP and intracellular ATP content exhibited a progressive reduction during the $10 \mathrm{~h}$ swimming period. Mean values of the percentage of motile spermatozoa, VAP, sperm track linearity (LIN) and intracellular ATP content recorded at the beginning of the movement period for sperm samples collected after intragonadal serotonin injection, were $82 \pm 7 \%, 162 \pm 15 \mu \mathrm{m} \mathrm{s}^{-1}, 0.33 \pm 0.12$ and $212 \pm 133 \mathrm{nmol} \times 10^{-9}$ spermatozoa $(n=9$ males $)$, respectively. The present study confirms the existence of a sperm "maturation process" along scallop genital ducts. In addition, the cessation of scallop sperm movement can be explained by the exhaustion of ATP content at the end of the movement phase.
\end{abstract}

Keywords: Spermatozoa / CASA / Maturation / Sperm motility / Bivalve / Pecten maximus

\section{Introduction}

A sperm "maturation process" along the genital tract was firstly described for mammalian spermatozoa which acquire their movement potential during their transit through the epididymis (Tournade 1913). This phenomenon was also reported in aquatic species such as rainbow trout (Oncorhynchuss mykiss; Morisawa and Morisawa 1986) and turbot (Psetta maxima; Dreanno 1998): in both species, spermatozoa acquire their potential for motility in the genital tract. In mollusk bivalves, spermatozoa collected from the testis of pearl oysters (Pinctada fucata martensii) cannot be activated after dilution in seawater while sperm motility was activated in alkaline

a Corresponding author: marc.suquet@ifremer.fr seawater buffered at $\mathrm{pH} 9.4$, suggesting an in vitro maturation of testicular spermatozoa (Ohta et al. 2007; Demoy-Schneider et al. 2012). The flagellar beat frequency was lower for Pacific oyster (Crassostrea gigas) sperm collected by testicular stripping compared to values recorded for sperm released after transfer through the genital ducts, following serotonin (5hydroxytryptamine) injection or thermal shock (Cosson et al. 2008a).

Bivalve sperm can be collected by gonad scarification but also by using different techniques to induce ejaculation (Velasco et al. 2007). For example, sperm release of American oysters (Crassostrea virginica) was observed following a rapid temperature increase or after the addition of oocytes in seawater surrounding animals (Galstoff 1940). Serotonin 
injection induced spawning in six bivalve species, mostly in males and rarely in females (Gibbons and Castagna 1984). The characteristics of sperm, collected after mollusk sperm shedding, were estimated in a few species: mussel (Mytilus edulis, Everett et al. 2004; Jha et al. 2007), Pacific oyster (Cosson et al. 2008a; Suquet et al. 2012) and sea urchin (Anthocidaris crassispina; Au et al. 2000). Sperm fertilisation capacity of two Caribbean scallops (Argopecten nucleus and Nodipecten nodosus) was not influenced by stimulation technique, including temperature shock and serotonin or prostaglandin injection (Velasco et al. 2007).

The movement duration of sperm is very different among aquatic species: fish sperm movement duration is generally short, ranging from $40 \mathrm{~s}$ up to $20 \mathrm{~min}$ in marine species (Cosson 2010; Cosson et al. 2008b). Sperm movement duration is generally longer in invertebrates, depending on species, lasting from $2 \mathrm{~h}$ up to $20 \mathrm{~h}$ in sea urchin (Ohtake et al. 1996).

The great scallop (Pecten maximus) is hatchery produced in Norway, Ireland, France and the UK with worldwide production reaching 68 t (FAO 2010). Nevertheless, artificial reproduction of great scallop is poorly controlled in hatcheries: highly variable results were recorded after thermal shocks (Devauchelle et al. 1994a). Furthermore, information on sperm biology remains limited (Devauchelle and Mingant 1991; Andersen et al. 2011). In this species, spermatozoa released through the ducts, after intragonadal serotonin injection or thermal shock, can be activated when diluted in seawater, and simultaneously a high respiration rate is initiated. In contrast, a low motility, estimated using an arbitrary scale (from 1 immotile to 5 fully motile), was observed after the dilution of intratesticular spermatozoa into seawater, suggesting a sperm capacitation phenomenon occurring during gamete transit through the genital ducts (Faure et al. 1994a). A decrease of the percentage of motile sperm was recorded two hours after sperm activation while no movement was observed after $4 \mathrm{~h}$ (Faure et al. 1994b).

Recently, a new computer assisted sperm analysis (CASA) system has been developed for Image J. This freely accessible software, primarily designed for the analysis of fish sperm movement, quantifies fine parameters such as swimming speed (Wilson-Leedy and Ingermann 2007).

The aims of the present paper are to describe the changes in scallop sperm movement characteristics in relation to (1) sperm release technique (thermal shock versus serotonin injection), (2) sperm collection technique (testis sampling versus serotonin injection), (3) sperm sampling location along the genital tract, (4) in vitro sperm maturation and (5) time post sperm activation.

\section{Material and methods}

\subsection{General procedure}

Adult scallops (mean weight \pm SD: $174 \pm 32 \mathrm{~g}$, mean length \pm SD: $111 \pm 7 \mathrm{~mm}$ ) were caught from the bay of Brest (Finistère, France) at the beginning of their natural spawning season (March). They were then transferred to the Argenton experimental hatchery where they were maintained in flow through seawater tanks (volume: $600 \mathrm{~L}$, flow rate: $30 \% \mathrm{~h}^{-1}$,
Table 1. Set parameters for CASA analysis of scallop spermatozoa movement.

\begin{tabular}{lc}
\hline Setting parameters & \\
\hline Frame rate (frame s & \\
Spermatozoa size range (pixels) & 25 \\
Minimum VAP for motile spermatozoa $\left(\mu \mathrm{m} \mathrm{s}^{-1}\right)$ & 1 to 500 \\
Minimum number of spermatozoa observed & 6 \\
Minimum track length (frames) & 30 \\
\hline
\end{tabular}

VAP: Velocity of the average path.

seawater: $17^{\circ} \mathrm{C}$ ) and fed daily with a mixture of two microalgae (Isochrysis galbana and Chaetoceros calcitrans: $10^{9}$ cells of each species/day/animal) for one month.

For intratesticular sperm study, scallops were dissected and sperm was sampled $(10 \mu \mathrm{l})$ using a micropipette and stored over ice until use. For the shed sperm study, males were treated with $100 \mu \mathrm{l}$ of a $10 \mathrm{mM}$ serotonin solution diluted in distilled water: serotonin was injected into male gonads and scallop were transferred in $2 \mathrm{~L}$ beakers filled with $0.5 \mathrm{~L}$ seawater $\left(17^{\circ} \mathrm{C}\right.$, filtered at $\left.1 \mu \mathrm{m}\right)$. A $10 \mu \mathrm{l}$ sperm sample was then pipetted into the beaker at the beginning of sperm shedding.

For intracellular ATP measurements, sperm samples were diluted in $5 \mathrm{ml}$ filtered $(1 \mu \mathrm{m})$ seawater and the sperm suspension was filtered at $60 \mu \mathrm{m}$. Sperm samples of $500 \mu \mathrm{l}$ were immediately frozen in liquid nitrogen. Intracellular ATP content was measured (triplicates) by bioluminescence (kit ATP lite, Perkin Elmer) using a microplate reader (Biotech Synergy HT) as previously described (Suquet et al. 2010). After dilution to $1 / 500$ in $1 \mu \mathrm{m}$ filtered seawater, sperm concentration was determined by Coulter Counter (duplicates). Sperm motility was estimated using a two-step dilution procedure: firstly, $10 \mu \mathrm{l}$ sperm was diluted in $250 \mu$ l seawater ( $\mathrm{pH} 7.8$, $17{ }^{\circ} \mathrm{C}$ ) and secondly, $10 \mu \mathrm{l}$ of the first suspension was diluted again in $250 \mu \mathrm{l}$ seawater (final dilution 1:625). Since preliminary results showed that the addition of bovine serum albumin (BSA) in seawater significantly increased $(p<0.01$, $n=3$ males) sperm velocity of the average path (VAP; with BSA: $194 \pm 46 \mu \mathrm{m} \mathrm{s}^{-1}$, without BSA: $144 \pm 46 \mu \mathrm{m} \mathrm{s}^{-1}$ ) but not the percentage of motile spermatozoa $(83 \pm 5 \%$ and $84 \pm 4 \%$, respectively), $5 \mathrm{~g} \mathrm{~L}^{-1} \mathrm{BSA}$ were added to all media used to observe sperm motility. Sperm samples of $7 \mu$ l were transferred in Thomas cell and movement characteristics were observed under a phase contrast microscope (Olympus BX51, X 20 magnification), connected to a camera (Qicam Fast 1394). The percentage of motile spermatozoa was visually estimated in triplicate by counting 30 cells for each replicate. Sperm VAP was assessed using a computer assisted sperm analyser (CASA) plug-in developed for the Image J software (WilsonLeedy and Ingermann 2007). To describe the general movement of scallop sperm, the linearity (LIN = VSL/VAP, varying from 0 to 1 , corresponding to totally circular to straight sperm track respectively; VSL: straight-line velocity) was punctually assessed. Calibration settings used for the following experiments are presented in Table 1. All experiments were carried out on sperm from three different males. 


\subsection{Experimental design}

A set of five different experiments was carried out. First, the effect of sperm release technique was studied by comparing the movement characteristics of spermatozoa collected after intragonadal serotonine injection or thermal shock. In the latter case, scallops were transferred in a $0.1 \mathrm{~m}^{3}$ tank and water temperature was rapidly increased from 17 to $22^{\circ} \mathrm{C}$ (Andersen et al. 2011). When sperm were released, scallops were rapidly placed in $2 \mathrm{~L}$ beakers filled with $0.5 \mathrm{~L}$ seawater $\left(17^{\circ} \mathrm{C}\right.$, filtered at $1 \mu \mathrm{m})$.

Second, the possible effects of a "sperm maturation process" along the genital ducts were assessed by comparing the characteristics of testicular spermatozoa to those of sperm shed by males after serotonin injection. After the removal of the scallop upper shell, intratesticular sperm was pipetted from gonads. The same males were then treated with serotonin solution. The movement of sperm collected after serotonin injection was observed just after sperm shedding, using only the second step dilution because sperm was collected in seawater and thus already diluted. ATP content of (a) intratesticular sperm and (b) spawned sperm collected post serotonin injection was assessed.

Third, after the removal of the scallop upper shell, the movement characteristics of sperm sampled at different levels of the genital tract were compared: (1) distal section of the testes, close to the female gonad; (2) median section of the testes; (3) proximal section of the testes; (4) lumen of the proximal section and (5) gonopore close to the kidneys.

Fourth, to assess in vitro sperm maturation capacity, testicular sperm samples were incubated in seawater (SW), seawater containing $2 \mathrm{mM}$ serotonine $(\mathrm{SW}+\mathrm{S})$ or $10 \mathrm{mM}$ caffeine $(\mathrm{SW}+\mathrm{C})$. Sperm movement characteristics were recorded during a 5 min period.

Fifth, changes in sperm movement characteristics and ATP content were described over a $10 \mathrm{~h}$ period. Sperm was collected after serotonin induction, as described above. Sperm movement was triggered in filtered seawater (1:1000). Sperm motility parameters and ATP content were estimated hourly.

\subsection{Data analysis}

Data were presented as mean \pm SD. Percentages were arcsin square-root transformed to normalize variances. Data were compared using Student's $t$-test or two way analysis of variance. When significant differences were observed for ANOVA, a Fisher a posteriori test was used.

\section{Results}

Sperm shedding was observed in all treated animals between 10 and 30 min after serotonin injection. The corresponding motile spermatozoa exhibited forward motility and circular tracks. Sperm shedding was observed for $20 \%$ scallops, from 1 to $4 \mathrm{~h}$ after a rapid increase of temperature (from 17 to $22^{\circ} \mathrm{C}$ ). Regardless of sperm collection technique (e.g. thermal shock

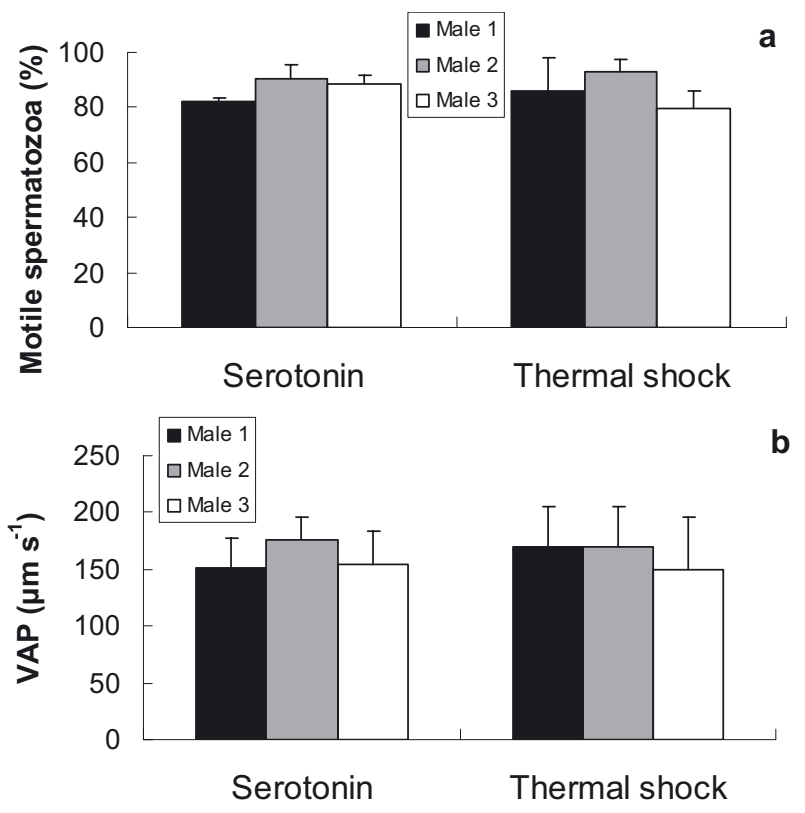

Fig. 1. Effect of the release technique (serotonin injection versus thermal shock) on sperm movement characteristics: (a) changes in the percentage of motile sperm, (b) changes in the velocity of the average path (VAP).
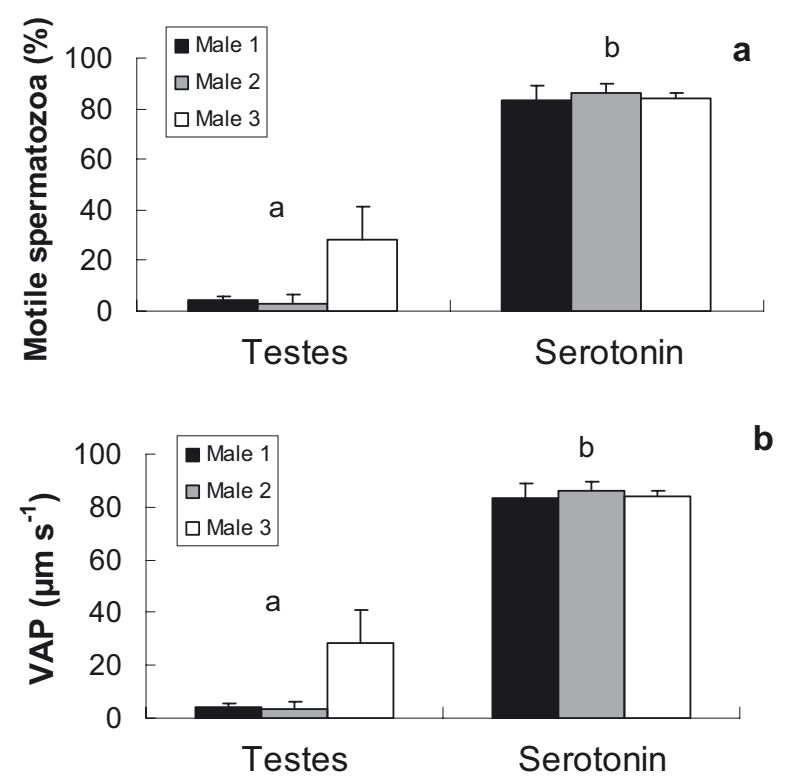

Fig. 2. Effect of the collection technique (testes sampling versus serotonin injection) on sperm movement characteristics: (a) changes in the percentage of motile sperm, (b) changes in the velocity of the average path (VAP); different letters refer to significantly different results.

versus serotonin injection), no significant differences were observed regarding the percentage of motile spermatozoa or the VAP (Fig. 1).

After activation in SW, intratesticular spermatozoa as well as serotonin shed ones exhibited forward motility without any periods of rest. Compared to testicular sperm, a significantly higher percentage of motile spermatozoa $(p<0.001)$ and VAP $(p<0.001)$ were observed for sperm shed after serotonin injection (Fig. 2). The ATP content of shed spermatozoa 

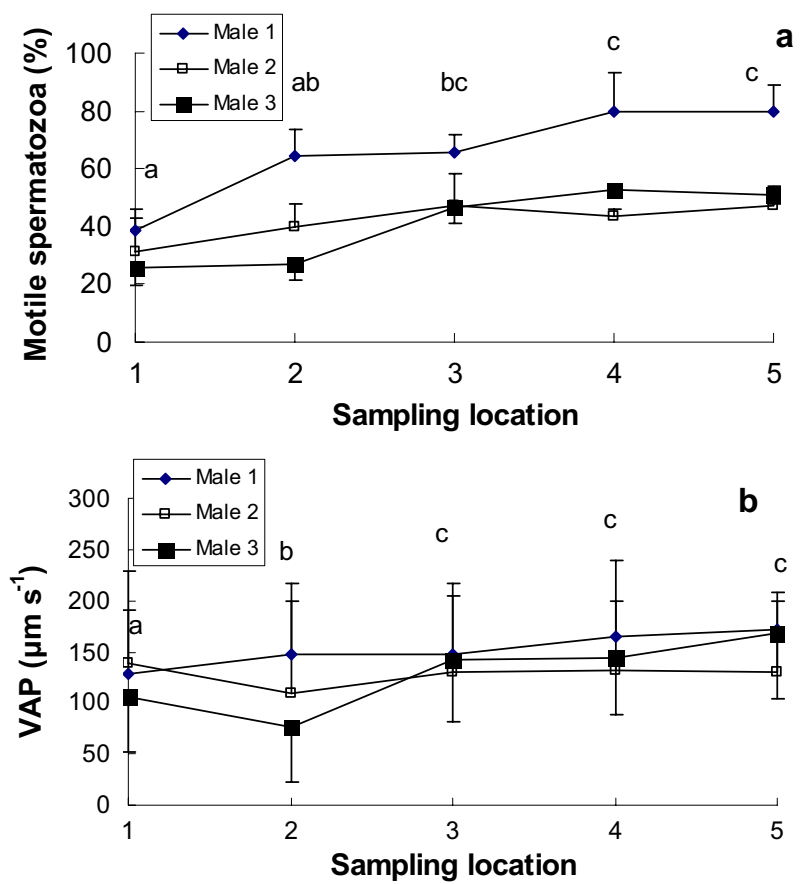

Fig. 3. Effect of sampling location (1: distal section of the testes, 2: median section of the testes, 3: proximal section of the testes, 4: lumen of the distal section and 5: gonopore) on sperm movement characteristics: (a) changes in the percentage of motile sperm, (b) changes in the velocity of the average path (VAP); different letters refer to significantly different results.

$\left(212 \pm 124 \mathrm{nmol} \times 10^{-9}\right.$ spermatozoa) was significantly higher $(p<0.05)$ than the mean value recorded for intratesticular spermatozoa $\left(62 \pm 39 \mathrm{nmol} \times 10^{-9}\right.$ spermatozoa). From the distal part of testes up to the gonopore, a significant increase in the percentage of motile spermatozoa $(p<0.001)$ and VAP $(p<0.05)$ was observed (Fig. 3). The percentage of motile sperm was significantly different among males $(p<0.001)$, the highest values being recorded in male 1 compared to 2 and 3 .

A significant increase in the percentage of motile sperm $(p<0.001)$ and VAP $(p<0.001)$ were observed during the 5 min incubation of testicular sperm in $\mathrm{SW}, \mathrm{SW}+\mathrm{S}$ and $\mathrm{SW}+\mathrm{C}$ (Fig. 4). In addition, a significantly higher increase in the percentage of motile spermatozoa $(p<0.05)$ was recorded in $\mathrm{SW}+\mathrm{S}$ and $\mathrm{SW}+\mathrm{C}$ compared to $\mathrm{SW}$. A significantly higher VAP $(p<0.001)$ was assessed, incubating testicular sperm in $\mathrm{SW}+\mathrm{C}$, compared to $\mathrm{SW}$ or $\mathrm{SW}+\mathrm{S}$. In addition, the VAP observed in $\mathrm{SW}+\mathrm{S}$ was significantly higher than values observed in SW. Then, a significant interaction $(p<0.001)$ was observed between sperm activating solution and time post activation.

The percentage of motile spermatozoa, VAP and intracellular ATP content exhibited a significant reduction during the $10 \mathrm{~h}$ swimming period (Fig. $5 ; p<0.001$ for the three parameters). In addition, a significant difference was recorded between males for these parameters $(p<0.001)$ : the highest values of the percentage of motile cells, VAP and ATP content were observed for male 2 as compared to those recorded in males 1 and 3 .
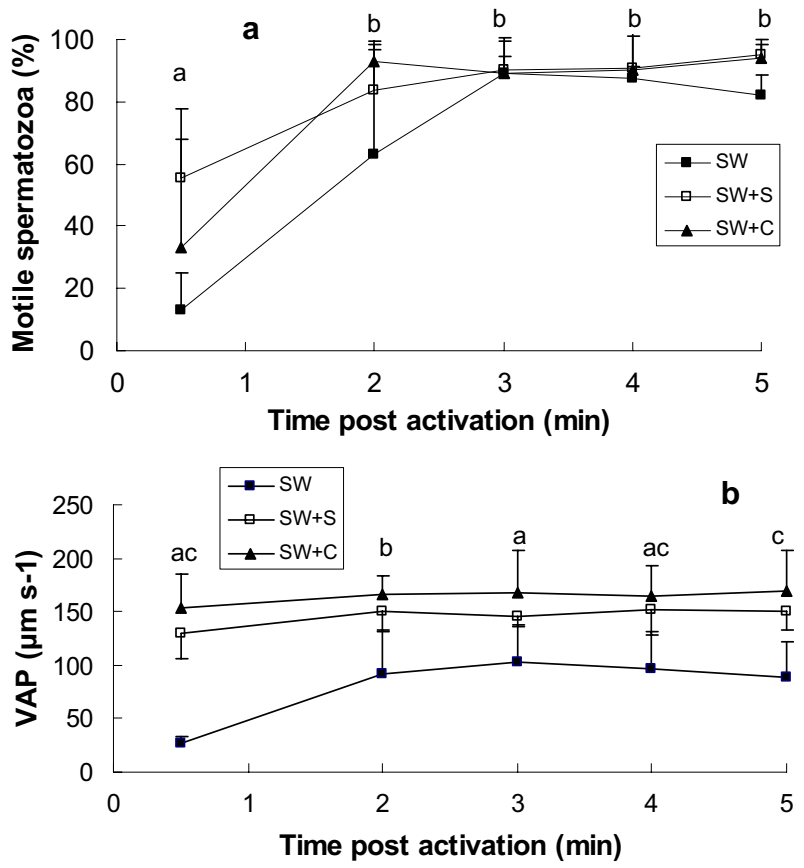

Fig. 4. Effect of in vitro testicular sperm maturation on sperm characteristics (SW: seawater, $\mathrm{SW}+\mathrm{S}$ : seawater $+2 \mathrm{mM}$ serotonin, $\mathrm{SW}+\mathrm{C}$ : seawater $+10 \mathrm{mM}$ caffeine): (a) changes in the percentage of motile sperm, (b) changes in the velocity of the average path (VAP); different letters refer to significantly different results.

\section{Discussion}

Thermal shock is classically used to collect gametes in bivalves (Galstoff 1940). However, this method is not reliable in scallop because spermiation is induced after a period of $30 \mathrm{~min}$ up to $4 \mathrm{~h}$, after temperature increase (Devauchelle et al. 1994b). According to previous results observed in six bivalves species (Gibbons and Castagna 1984), intragonadal serotonin injection is an efficient technique to induce sperm shedding in scallop because sperm was collected in all induced animals within $30 \mathrm{~min}$ after injection. Serotonin, a neurotransmitter, is present in the nervous system of several mollusks (Welsh and Moorhead 1960). In scallops, serotonin neurons are mainly distributed in the pedal and cerebral ganglia. The serotonergic system of the scallop gonad is more developed in males compared to females, explaining the absence of oocyte release after serotonin injection in this species (Paulet et al. 1993). Sperm release technique (thermal shock versus serotonin injection) had no effect on the movement characteristics of scallop sperm. The percentage of motile spermatozoa and the fertilisation capacity were similar in scallop or Pacific oyster, regardless of which sperm release technique was used (Faure 1996).

In the present study, the mean values of the percentage of motile spermatozoa shed after intragonadal serotonin injection, VAP, LIN and intracellular ATP content recorded at the beginning of the movement period on 9 scallops were $82 \pm 7 \%$, $162 \pm 15 \mu \mathrm{m} \mathrm{s}^{-1}, 0.33 \pm 0.12$ and $212 \pm 133 \mathrm{nmol} \times 10^{-9}$ spermatozoa, respectively. The mean sperm movement characteristics measured by Faure (1996) on scallop sperm are close to those of the present work, except for linearity which was 

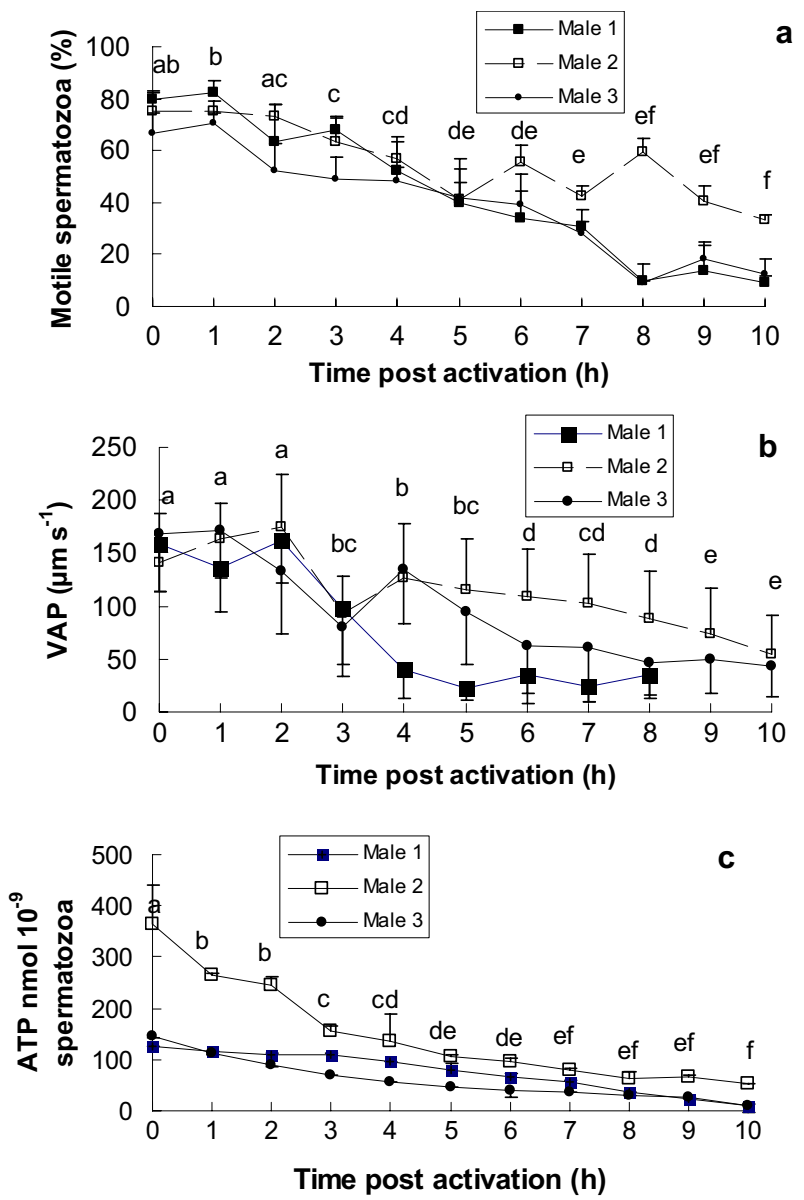

Fig. 5. Effect of time post activation on sperm characteristics: (a) changes in the percentage of motile sperm, (b) changes in the velocity of the average path (VAP), (c) changes in intracellular ATP content; different letters refer to significantly different results.

higher (0.65 to 0.75$)$, suggesting a less circular path assessed in this previous study which used a different CASA device (Modcell) than that one used in the present work (Image J). Compared to scallop, lower values of VAP were reported in blue mussels (Mytilus edulis): $103 \pm 2 \mu \mathrm{m} \mathrm{s}^{-1}$ (Jha et al. 2007) or Pacific oyster: $72 \pm 14 \mu \mathrm{m} \mathrm{s}^{-1}$ (Faure 1996). On the other hand, a higher swimming speed was assessed in black-lip-pearl oysters: $221 \pm 12 \mu \mathrm{m} \mathrm{s}^{-1}$ (Demoy-Schneider et al. 2012). The mean intracellular ATP content of scallop sperm is high compared to that measured in different mollusk species (from 4 to $45 \mathrm{nmol} \times 10^{-9}$ spermatozoa; Suquet et al. 2010). However, an even higher ATP content was assessed in black-lip-pearl oysters: $700 \mathrm{nmol} \times 10^{-9}$ spermatozoa (Demoy-Schneider et al. 2012).

The gradual increase of the percentage of motile spermatozoa and VAP observed in the present work from the distal part of testes up to the gonopore, confirms the existence of a sperm "maturation process" along scallop genital ducts as previously suggested (Faure et al. 1994a). Additionally, the percentage of motile spermatozoa assessed at the gonopore $(60 \pm 18 \%)$ is low compared to results recorded for sperm shed after serotonin injection $(82 \pm 7 \%)$. This suggests a complementary role of serotonin in the sperm "maturation process" which was in vitro demonstrated in Pacific oyster: the flagellar beat frequency of testicular spermatozoa activated in seawater raised up to $20 \mathrm{~Hz}$ while the frequency of testicular sperm activated in seawater containing $10 \mathrm{mM}$ serotonin, reached $40 \mathrm{~Hz}$, close to values assessed for sperm ejaculated after serotonin injection of gonads (Cosson et al. 2008a). On the other hand, the present work shows that scallop VAP is not different between gonopore collected $\left(158 \pm 60 \mu \mathrm{m} \mathrm{s}^{-1}\right)$ and serotonin shed $\left(162 \pm 15 \mu \mathrm{m} \mathrm{s}^{-1}\right)$ sperm. A partial in vitro maturation of testicular sperm is observed when incubated in seawater. A supplementary step of the 'maturation process' was observed when testicular sperm was incubated using chemicals belonging to the cAMP signaling process such as caffeine and serotonin: higher percentages of motile spermatozoa and VAP were recorded compared to sperm incubated in SW. The initiation of sperm movement is regulated by cAMP, stimulating protein phosphorylation by cAMP dependant protein kinase (Tash 1990).

Shorter movement durations of scallop sperm were previously recorded: $4 \mathrm{~h}$ (Faure et al. 1994b) as compared to the present study (more than $10 \mathrm{~h}$ ). Sperm movement period may depend on many factors including animal maturation stage and sperm initial ATP content. Compared to scallop, the progressive movement of Pacific oyster sperm was maintained for a longer duration (20 to 24 h; Suquet et al. 2010). The decrease of scallop ATP level is gradual: a decrease of $19 \pm 11 \%$ of the initial content occurs after one hour post activation, which reaches a $40 \pm 25 \%$ after $3 \mathrm{~h}$ and followed by further decrease from 3 to $10 \mathrm{~h}$ post activation. The decrease of sperm ATP content of two sea urchin species (Arbacia lixula and Paracentrotus lividus) was more rapid: 54 to $79 \%$ of their initial ATP content was exhausted 5 min post activation (Mita et al. 1994). The long movement duration and the immediate increase in oxygen consumption determined after sperm activation (from 20 to $90 \mu \mathrm{mol} \mathrm{O} \mathrm{min}^{-1} \mathrm{mg}^{-1}$ protein; Faure et al. 1994a) suggest that scallop sperm could partially restore the energy content catabolised during the movement period. Then, the cessation of scallop sperm movement 8 to $10 \mathrm{~h}$ post activation could be caused by a limiting concentration of ATP amounting for a $90 \pm 4 \%$ loss, as compared to the initial ATP content. On the contrary, $94 \%$ of the initial ATP content of Pacific oyster sperm was still assessed at the end of the movement period, suggesting that the cessation of sperm movement was not caused by a low ATP level in this species, but rather by drastic changes in sperm morphology (Suquet et al. 2010). The causes of scallop sperm movement cessation will be further explored by testing the ability of spermatozoa to perform a second swimming phase after incubation in a non activating medium, as previously described in turbot (Dreanno 1998).

Inter-individual variations of sperm characteristics were observed in the present study and concern the percentage of motile spermatozoa, VAP and ATP content. These results confirm the individual variations of sperm traits previously recorded in scallop but also in Pacific oyster (Devauchelle et al. 1994b). These inter-individual variations of sperm characteristics must be further explored to determine their physiological causes and whether they affect the fertilisation capacity of breeders.

In conclusion, the present study confirms the existence of a sperm "maturation process" along scallop genital ducts. The 
cessation of scallop sperm movement can be explained by the exhaustion of intracellular ATP content at the end of the movement phase.

Acknowledgements. This work was supported by the European project Reproseed (FP7- KBBE-2009-3).

\section{References}

Andersen S., Christophersen G., Magnesen T., 2011, Spat production of the great scallop (Pecten maximus): a roller coaster. Can. J. Zool. 89, 579-598.

Au D.W.T., Chaing M.W.L., Wu R.S.S., 2000, Effects of cadmium and phenol on motility and ultrastructure of sea urchin and mussel spermatozoa. Arch. Environ. Contam. Toxicol. 38, 455-463.

Cosson, J., 2010, Frenetic activation of fish spermatozoa flagella entails short term motility, portending their precocious decadence. J. Fish Biol. 76, 240-279.

Cosson J., Faure C., Devauchelle N., Suquet, M., 2008a, Activation of oyster (Crassostrea gigas) sperm motility. In: Physiomar 08. 1-4 September 2008, Brest, France. Book of abstracts, http:// archimer.ifremer.fr/doc/2008/acte-4600.pdf

Cosson J., Groison A.L., Suquet M., Fauvel C., Dreanno C., Billard R., 2008b, Studying sperm motility in marine fish: an overview on the state of the art. J. Appl. Ichthyol. 24, 460-486.

Demoy-Schneider M., Levêque A., Schmitt N., Le Pennec M., Cosson J., 2012, Motility activation and metabolism characteristics of the black-lip-pearl oyster Pinctada margaritifera var: cumingii (Jameson, 1901). Theriogenology 77, 53-64.

Devauchelle N., Mingant C., 1991, Review of the reproductive physiology of the scallop, Pecten maximus, applicable to intensive aquaculture. Aquat. Living Resour. 4, 41-51.

Devauchelle N., Micarelli, P., Guerrier, P., Desilets, J., 1994a, The neurohormonal induction of the release of oocytes and sperm from Pecten maximus. Can. Tech. Rep. Fish. Aquat. Sci. 1, 148158.

Devauchelle N., Faure C., Girard J.P., 1994b, The quality of sperm of two bivalves: the oyster, Crassostrea gigas and the scallop, Pecten maximus. In: Muir J., Sevila F (Eds.) Measures for success, Eur. Aquac. Soc., Spec. Publ. 21, 214-2166.

Dreanno C., 1998, Régulation de la mobilité des spermatozoïdes de turbot (Psetta maxima) et de bar (Dicentrarchus labrax). Ph.D. Thesis, Fac Vie-santé, Univ. Rennes.

Everett E.M., Williams P.J., Gibson G., Stewart D.T., 2004, Mitochondrial DNA polymorphisms and sperm motility in Mytilus edulis (Bivalvia: Mytilidae). J. Exp. Zool. 301A, 906910.

FAO, 2010. Fisheries and aquaculture information and statistics service. Food and Agriculture Organization of the United Nations, FAO, Rome.

Faure C., 1996, Paramètres physiologiques de l'émission et de l'activation des gamètes mâles de deux mollusques bivalves, la coquille Saint Jacques Pecten maximus (L.) et l'huître creuse Crassostrea gigas (Thunberg). Ph.D. Thesis, Fac Diderot, Univ. Paris VII, Paris.

Faure C., Devauchelle N., Girard J.P., 1994a, Ionic factors affecting motility, respiration and fertilization rate of the sperm of the bivalve Pecten maximus (L). J. Comp. Physiol. 164B, 444-450.
Faure C., Devauchelle N., Girard J.P., Cosson J., 1994b, The quality of Pecten maximus sperm. In: Proc. ${ }^{\text {th }}$ Int. Pectinid Workshop, 22-27 April 1993, Nanaimo, Canada. Can. Tech. Rep. Fish. Aquat. Sci. 1, 28-37.

Galstoff P.S., 1940, Physiology of reproduction of Ostrea virginica. III. Stimulation of spawning in the male oyster. Biol. Bull. 78, 117-135.

Gibbons M.C., Castagna M., 1984, Serotonin as an inducer of spawning in six bivalve species. Aquaculture 40, 189-191.

Jha M., Côté J., Hoeh W.R., Blier P.U., Stewart D.T., 2007, Sperm motility in Mytilus edulis in relation to mitochondrial DNA polymorphisms: implications for the evolution of doubly uniparental inheritance in bivalves. Evolution 62, 99-106.

Mita M., Fujiwara A., De Santis R., Yasumasu I., 1994, High energy phosphate compounds in spermatozoa of the sea urchin Arbacia lixula and Paracentrotus lividus. Comp. Biochem. Physiol. 109A, 269-275.

Morisawa S., Morisawa M. 1986, Acquisition of potential for sperm motility in rainbow trout and chum salmon. J. Exp. Biol.126, 8996.

Ohta H., Kawamoto T., Isowa K., Aoki H., Hayashi M., Narita T., Komaru A., 2007, Motility of spermatozoa obtained from testes of Japanese pearl oyster Pinctada fucata martensii. Fish. Sci. 73, $107-111$.

Ohtake T., Mita M., Fujiwara A., Tazawa E., Yasumasu I., 1996, Degeneration of respiratory system in sea urchin spermatozoa during incubation in seawater for long duration. Zool. Sci. 13, 857-863.

Paulet Y.M., Donval A., Bekhadra F., 1993, Monoamines and reproduction in Pecten maximus, a preliminary approach. Invert. Reprod. Develop. 23, 89-94.

Suquet M., Labbe C., Brizard R., Donval A., Le Coz J.R., Quere C., Haffray P., 2010, Changes in motility, ATP content, morphology and fertilization capacity during the movement phase of tetraploid Pacific oyster (Crassostrea gigas) sperm. Theriogenology 74, 111-117.

Suquet M., Cosson J., Donval A., Labbé C., Boulais M., Haffray P., Bernard I., Fauvel C., 2012, Marathon versus sprint racers: an adaptation of sperm characteristics to the reproductive strategy of Pacific oyster, turbot and seabass. J. Appl. Ichthyol. 28, 956-960.

Tash J.S., 1990, Role of cAMP, calcium, and protein phosphorylation in sperm motility, Boston, CRC Press.

Tournade A., 1913, Différence de motilité des spermatozoïdes prélevés dans les différents segments de l'épididyme. C. R. Soc. Biol. 74, 738-739.

Velasco L.A., Barros J., Acosta E., 2007, Spawning induction and early development of the Caribbean scallops Argopecten nucleus and Nodipecten nodosus. Aquaculture 266, 153-165.

Welsh J.H., Moorhead M., 1960, The quantitative distribution of 5hydroxytryptamine in the invertebrates, especially in their nervous system. J. Neurochim. 6, 146-169.

Wilson-Leedy J.G., Ingermann R.L., 2007, Development of a novel CASA system based on open source software for characterization of zebrafish sperm motility parameters. Theriogenology 67, 661672. 